\title{
Automação Aplicada no Sistema de Transmissão Mecânica Automotiva
}

\author{
Automation Applied in the Automotive Mechanical Transmission System
}

\section{Luiz Thiago do Sacramento Bezerra ${ }^{1}$ (D)htps://orcid.org/0000-0002-5288-2127}

\section{Diogo Roberto Raposo de Freitas ${ }^{2}$ (Dhttps://orcid.org/0000-0002-5023-699X}

\footnotetext{
${ }^{1}$ Pós-graduação em Gestão da Produção e Automação Industrial, Faculdade de Tecnologia SENAI Pernambuco, Recife, Brasil.

${ }^{2}$ Escola Politécnica de Pernambuco, Universidade de Pernambuco, Recife, Brasil.

E-mail do autor principal: Luiz Thiago Bezerra thiagosacramento_pe@hotmail.com
}

\section{RESUMO}

Entre 2012 e 2016, a comercialização de veículos equipados com tecnologias capazes de dispensar a utilização da embreagem e das trocas de marchas manuais por parte dos motoristas, incluindo as transmissões automatizadas, cresceu 13,5\%. Essa tendência de crescimento está relacionada com um aumento do conforto e segurança na condução do automóvel, proporcionada pela automação aplicada nos diferentes sistemas de transmissões, além de aperfeiçoar o desempenho de seus componentes. Este artigo foca na aplicação da automação em um sistema de transmissão mecânica utilizada nos automóveis de passeio. Na metodologia utilizada, optou-se pelo método bibliográfico, para obtenção de conceitos e definições apropriados ao objeto de pesquisa. Neste estudo, deu-se um enfoque especial aos modelos de transmissões automatizadas denominadas pela montadora de ASG (Automated Sequential Gearbox) gerenciadas de forma eletro-hidráulica ou eletromecânica, ambas conhecidas como tecnologia I-Motion (Intelligent Motion). Os benefícios gerados pela automação no processo de troca de marchas destes veículos são: maior nível de segurança e conforto, reduzindo a fadiga do condutor; precisão e otimização dos componentes; redução de até $5 \%$ no consumo de combustível e emissões de poluentes, especialmente $\mathrm{CO}_{2}$.

PALAVRAS-CHAVE: Automação automotiva; Transmissão Automotiva; Segurança; Ergonomia.

\section{ABSTRACT}

Between 2012 and 2016, vehicles equipped with technologies capable of exempting the use of clutch and manual gear shifts by motorists, including automated transmissions, grew by $13.5 \%$. This trend of growth is related to an increase in comfort and safety in the driving of the automobile, provided by the automation applied in the different transmission systems in addition to optimizing the performance of its components. This article refers to the understanding of the application of automation in a mechanical transmission system used in passenger cars. In the methodology used, we opted for the bibliographic method, to obtain concepts and definitions appropriate to the research object. In this study, a special focus was given to automated transmission models named Automated Sequential Gearbox (ASG), which are managed in an electro-hydraulic or electromechanical manner, both of which are also known as I-Motion (Intelligent Motion) technology. The benefits generated by the automation in the process of shifting gears of these vehicles are a greater level of safety and comfort, reducing the fatigue of the driver; precision and optimization of components; reduction of up to $5 \%$ in fuel consumption and emissions of pollutants, especially $\mathrm{CO}_{2}$.

KEY-WORDS: AutomotiveAutomation; Automotive Transmission; Safety; Ergonomics. 


\section{INTRODUÇÃO}

Este artigo tem como objetivo a disseminação de conhecimento sobre os conceitos e benefícios gerados pela automação no processo de troca de marchas, aplicados no sistema de transmissão mecânica automotiva, detalhando as características de funcionamento do sistema IMotion.

O estudo realizado visa esclarecer as características da automação em um sistema de transmissão mecânica automotiva, através de pesquisas bibliográficas, análise de dados e resultados. Optou-se em dividir o trabalho em três partes, sendo a primeira detalhando a importância e os conceitos da automação além das características de um sistema de transmissão com trocas manuais. A segunda parte do estudo aborda a tecnologia I-Motion que é aplicada nas transmissões automatizadas de alguns modelos de veículos da marca Volkswagen, buscando expor os benefícios deste sistema. A terceira parte tem como objetivo analisar os dados bibliográficos sobre dois tipos de transmissões automatizadas: eletro-hidráulico e eletromecânica, detalhando seus princípios de funcionamento e características. O capítulo final apresenta quais foram os resultados alcançados através das pesquisas bibliográficas trazendo a conclusão sobre os estudos realizados.

\section{AUTOMAÇÃO E O SISTEMA DE TRANSMISSÃO MECÂNICA}

Os princípios da automação na indústria automobilística sejam em processos ou em produtos, atinge fortemente 0 seguimento automobilístico oferecendo excelentes resultados em virtude das inovações tecnológicas. Dentre os diversos exemplos de sucesso, estão as transmissões automatizadas que podem operar de forma sequencial ou totalmente automática.

A automação pode ser definida como a tecnologia por meio da qual um processo ou procedimento é alcançado sem a assistência humana. É realizado utilizando um programa de instruções combinado a um sistema de controle que executa as instruções [5].

Segundo Bosch, A transmissão de um automóvel tem a função de fornecer as forças de tração e impulsão necessárias para induzir o movimento [1].
O sistema de transmissão mecânica é formado basicamente pelos seguintes componentes: carcaça da transmissão, carcaça da embreagem, engrenagens, sincronizadores, eixos, semieixos, rolamentos, juntas articuladas, eixos articulados, mecanismo de troca de marchas com alavanca de mudanças, diferencial e por uma embreagem.

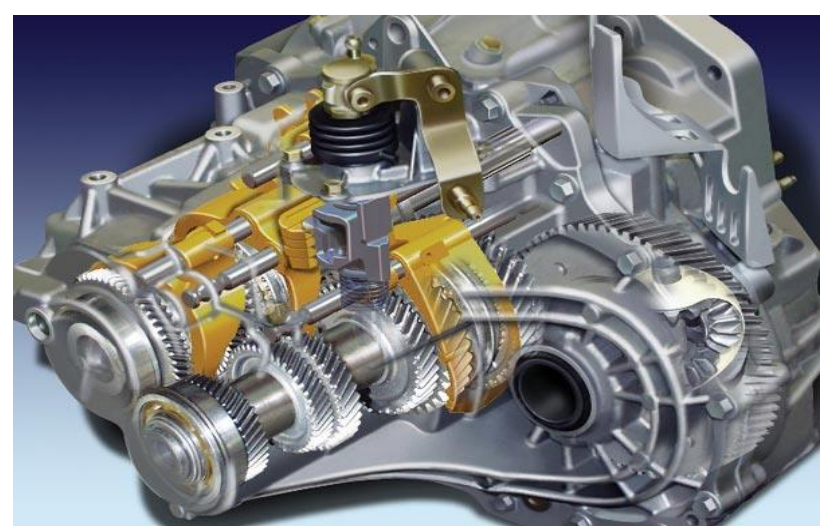

Figura 1:Componentes de uma transmissão mecânica. Fonte: Fonseca (2008).

Os autores Silveira e Santos trazem sua contribuição sobre o conceito de automação: "A automação é um conceito e um conjunto de técnicas por meio das quais se constroem sistemas ativos capazes de atuar com uma eficiência ótima pelo uso das informações recebidas do meio sobre o qual atuam" [9].

A aplicação da transmissão automatizada baseia-se em uma unidade de controle que gerencia o sistema eletro-hidráulico ou elétricomecânico (dependendo do modelo) no qual permite que o motorista mude de marcha sem utilizar o pedal de embreagem, de forma sequencial ou totalmente automática sem precisar comandar a alavanca de mudanças.

Entretanto Silveira e Santos afirmam que:

[...] com base nas informações, o sistema calcula a ação corretiva mais apropriada para a execução da ação e esta é uma característica de sistemas em malha fechada, conhecidos como sistemas de realimentação, ou seja, aquele que mantém uma relação expressa entre o valor da saída e o da entrada de referência do processo. Essa relação entrada/saída serve para corrigir eventuais valores de saída que estejam fora dos valores desejados. Para tanto, são utilizados controladores que, por meio da execução algorítmica de um programa ou circuito eletrônico, comparam o valor atual com o valor desejado, efetuando o cálculo para ajuste e correção" [9]. 
Sensor pode ser definido como sendo um dispositivo sensível a um fenômeno físico, como temperatura, umidade, luz, pressão, entre outros. Por meio desta sensibilidade, os sensores enviam u sinal, que por ser um simples abrir e fechar de contatos, para os dispositivos de medição e controle.

Os atuadores são dispositivos a serem acionados para executarem uma determinada força de deslocamento ou outra ação física, definida pelo sistema controlador por meio de uma ação de controle (maneira pela qual o controlador produz o sinal de controle). Podem ser magnéticos, hidráulicos, pneumáticos, elétricos ou de acionamento misto.

Num sistema automatizado, para que se possa calcula e implementar um controlador dedicado, é preciso modelar matematicamente todo o processo através de sua planta [9].

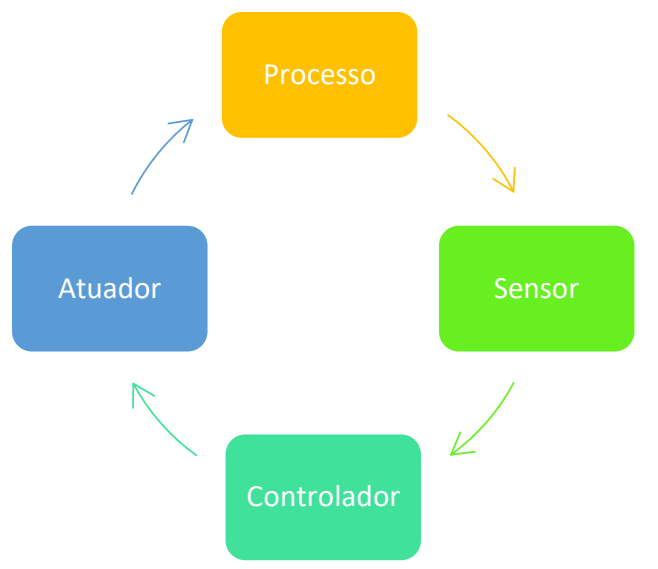

Figura 2: Diagrama de blocos de um sistema de automação.

Fonte: Silveira e Santos (1998).

\section{TRANSMISSÃO AUTOMATIZADA}

A transmissão automatizada usa tecnologia de ponta e é um sistema idêntico ao de um automóvel que possui transmissão com trocas manuais, a transmissão de força do motor é feita por intermédio de uma embreagem para acoplar ou desacoplar a transmissão de força do motor para as rodas. Porém a transmissão automatizada tem por característica realizar o acionamento da embreagem e o engate das marchas por meio de atuadores eletro-hidráulicos ou eletromecânicos comandados por uma unidade de controle da transmissão.
Este modelo de transmissão é muito confundido com o câmbio automático, porém existem diversas diferenças entre elas. A transmissão automatizada possui todos os componentes básicos de uma transmissão manual e é controlada por um sistema eletrônico responsável pelas operações de troca de marchas, já a transmissão automática não possui uma embreagem para transmitir o torque entre 0 motor e a transmissão, o componente responsável por esta função é o conversor de torque.

\subsection{Transmissão Automatizada Eletro hidráulica}

Este modelo de transmissão é gerenciado por uma unidade de controle que gerencia uma lógica complexa de funcionamento e permite a utilização da transmissão em dois modos de condução: modo "manual", na qual o motorista comanda a troca de marchas através da alavanca localizada sobre o túnel ou através de duas borboletas no volante e no modo "automático", onde o sistema eletrônico controla automaticamente as trocas de marchas. Para este sistema o pedal da embreagem foi eliminado e a tradicional alavanca do câmbio das transmissões mecânicas foi substituída por uma alavanca específica tipo "Joystick".

Os componentes da transmissão ASG são divididos em três partes que são fundamentais para o perfeito funcionamento do sistema, conforme representado nas Figuras 3 a 7 .

Conjunto mecânico: Uma transmissão mecânica sincronizada de cinco velocidades, com embreagem monodisco a seco, que são controladas por um servomecanismo hidráulico. Conjunto hidráulico: Bomba hidráulica, acumulador, êmbolos e válvulas, estes atuadores tem por função realizar automatização da transmissão. Conjunto elétrico: alavanca seletora, unidade de controle da transmissão, sensores e atuadores, interface com outras unidades de controle, basicamente tem a missão de gerenciar todo o conjunto hidráulico e fazer a interface com os outros sistemas do veículo e com o condutor [11]. 


\subsubsection{GRUPO ELETRO-HIDRÁULICO}

O grupo eletro-hidráulico é a parte encarregada, em nível prático e operacional, da seleção e engate da marcha desejada, a estrutura do sistema é formada por: um conjunto hidráulico para pressurização do circuito, um mecanismo de seleção de marcha para o comando do eixo seletor, um cilindro para o comando da embreagem, sensores e atuadores para o controle do sistema por meio de uma unidade de controle eletrônica [11].
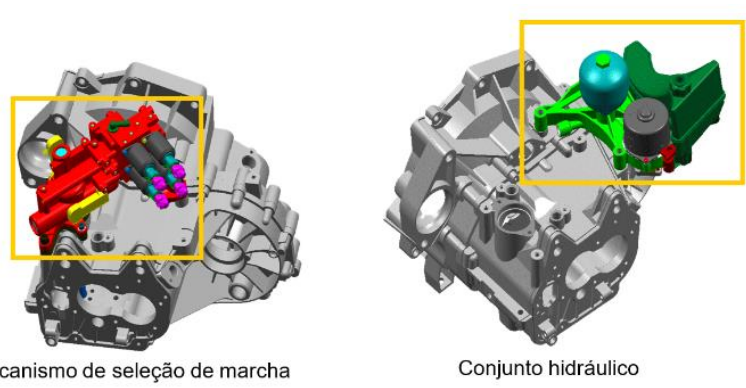

Figura 3: Visão geral do grupo eletro-hidráulico. Fonte: VOLKSWAGEN (2009).

O conjunto eletro-hidráulico encarrega-se de manter o sistema hidráulico pressurizado, a partir de um motor elétrico que trabalha com alimentação de corrente contínua e uma respectiva bomba hidráulica, para o acionamento dos êmbolos de seleção e engate das marchas, além do cilindro da embreagem que fica localizado na carcaça da transmissão [11].

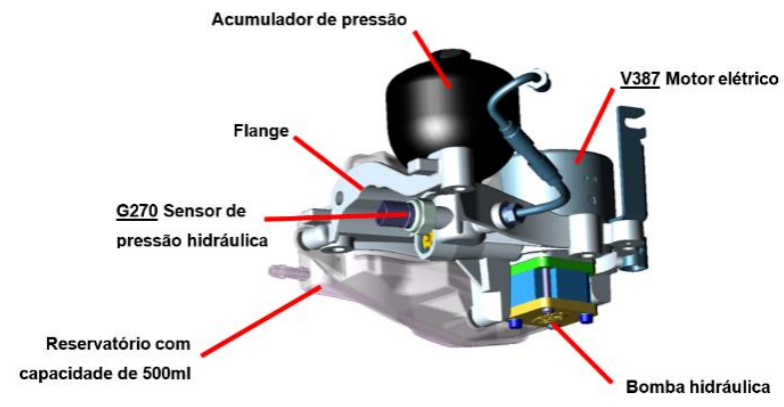

Figura 4: Conjunto hidráulico. Fonte: VOLKSWAGEN (2009).

O mecanismo de seleção de marchas executa as trocas de marchas na transmissão, possuindo êmbolos hidráulicos, sensores de identificação de marchas e válvulas atuadoras [11].

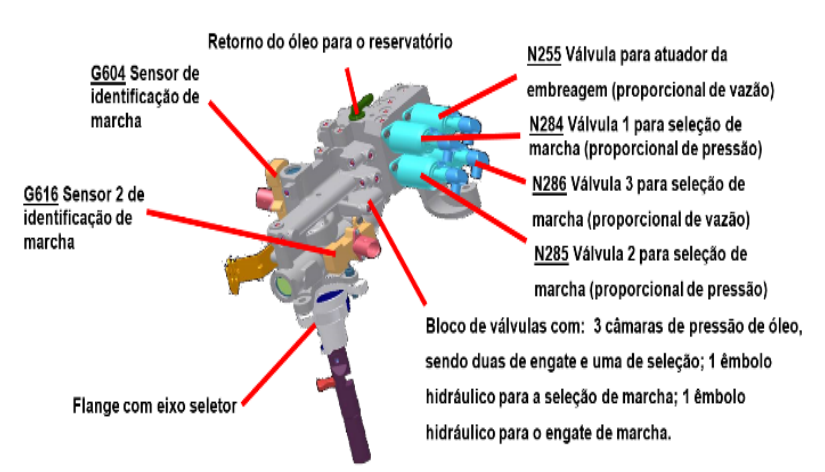

Figura 5: Mecanismo de seleção de marcha. Fonte: VOLKSWAGEN (2009). 


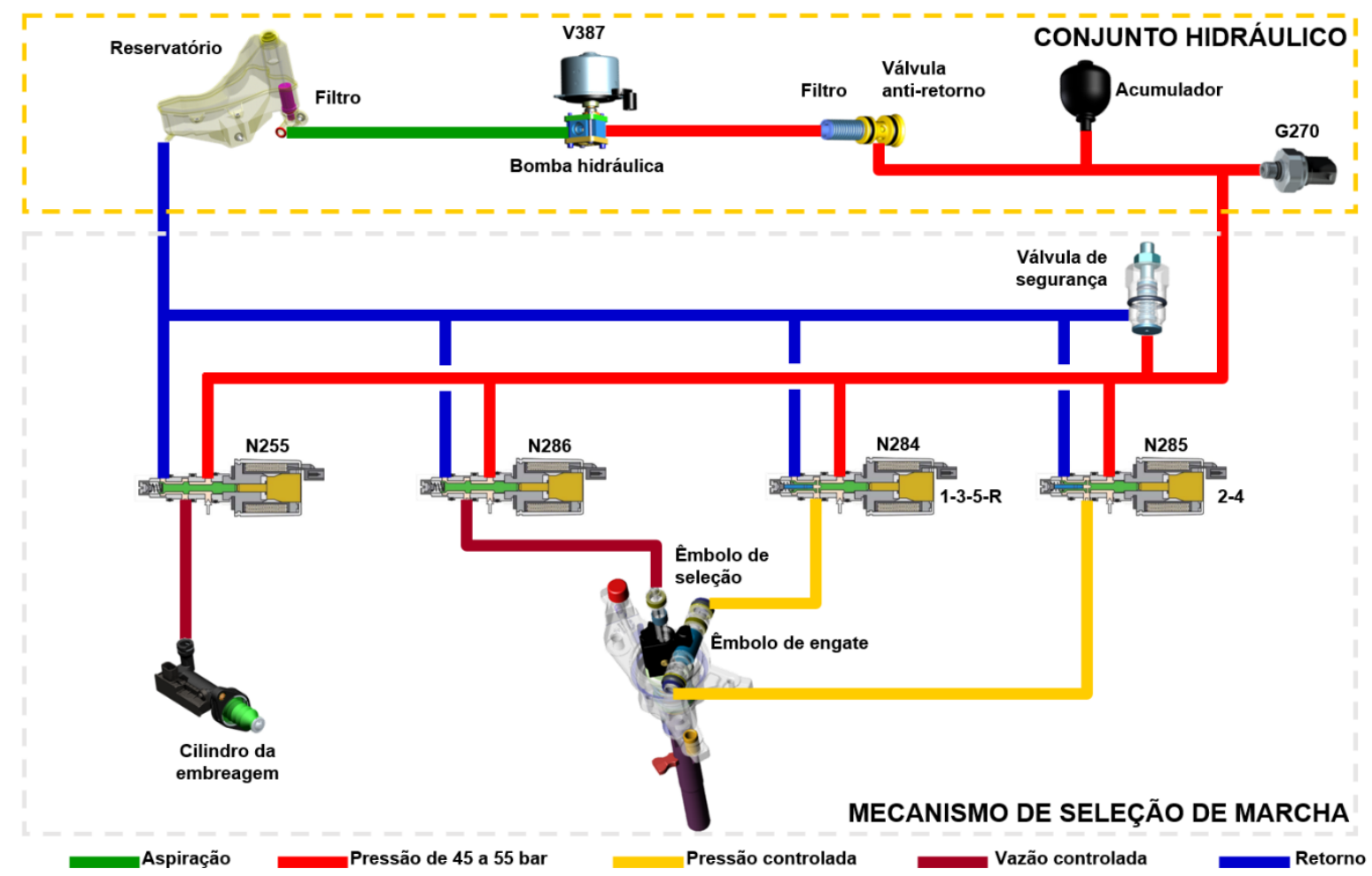

Figura 6: Diagrama hidráulico.

Fonte: VOLKSWAGEN (2009).

Para realização de troca das marchas, o óleo hidráulico é aspirado pela bomba, e de acordo com as necessidades do sistema o motor elétrico V387 para acionamento da bomba é ligado pela J217 (Unidade de controle da transmissão) e com isso o sistema hidráulico é pressurizado. O acumulador tem por função armazenar pressão do óleo suficiente para que a bomba elétrica não seja acionada constantemente. A 3217 checa o sinal elétrico enviado pelo sensor de pressão hidráulica G270 para determinar a pressão momentânea do sistema. As válvulas de pressão (N284 e N285) e de vazão (N255 e N286) ativam os êmbolos de acionamento de embreagem, seleção e engate de marchas. Após ser realizada a troca de uma determinada marcha, o óleo volta para o reservatório por meio da linha de retorno, onde é novamente aspirado pela bomba para seguir o processo de mudanças de marchas automatizado. Caso tenha um aumento de pressão inesperado o sistema hidráulico conta com uma válvula de segurança que abre diretamente para a linha de 81

\subsubsection{SISTEMA ELÉTRICO}

O gerenciamento eletrônico é realizado pela unidade de controle de transmissão J217, ela necessita de uma grande quantidade de informações de entrada que são enviadas pelos sensores, onde a partir destes sinais a J217 ajusta as magnitudes de correção por meio de seus atuadores, realizando assim as trocas de marchas de forma precisa e suave.

Segundo a Megneti Marelli [6],

a unidade de controle da transmissão é o coração e o cérebro do sistema e, considerando as exigências do motorista e as condições operacionais do veículo, ela gerencia as mudanças de marchas controlando a embreagem, as marchas e o motor.

DOI: $10.25286 /$ repa.v4i3.1182 


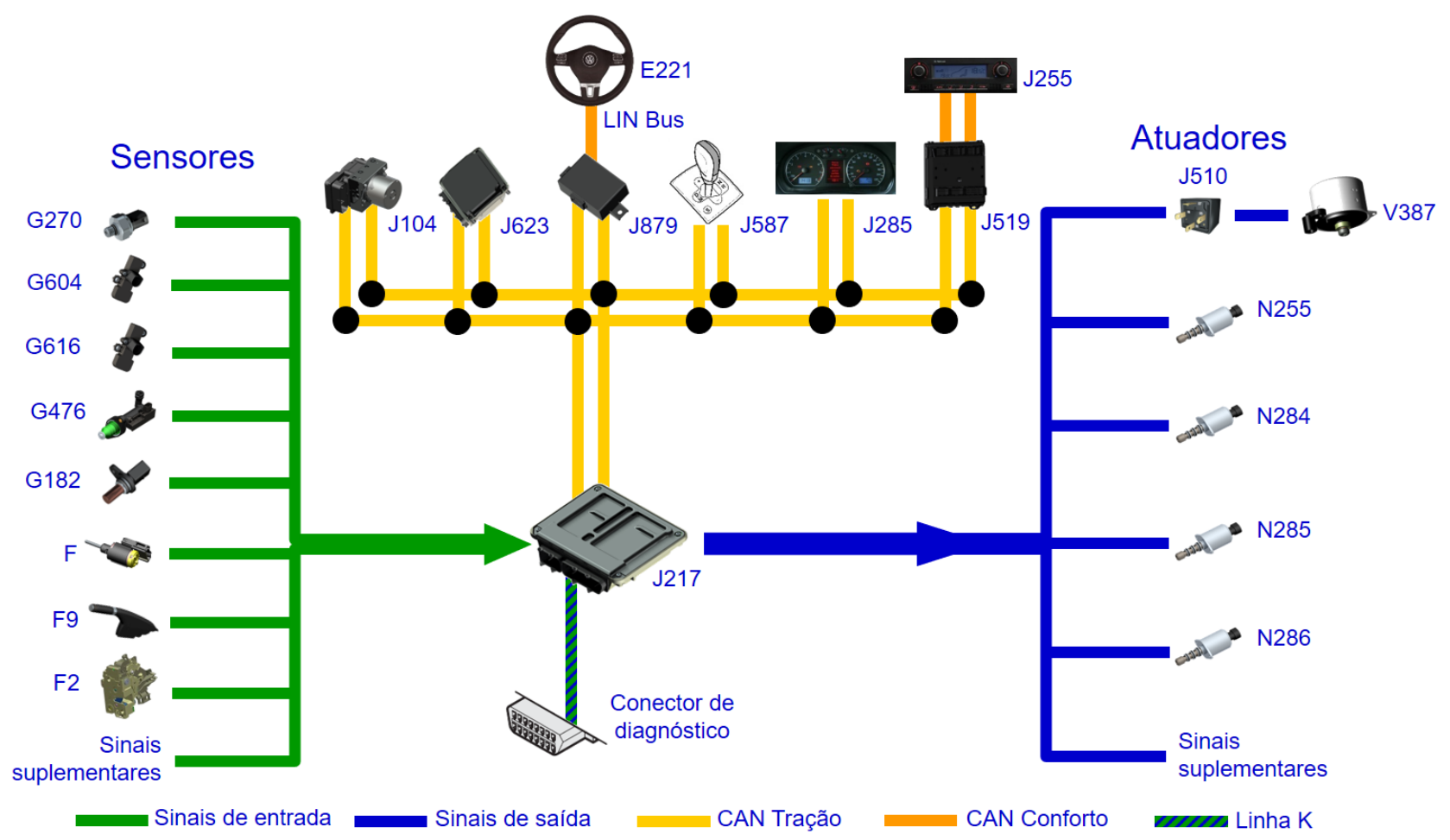

Figura 7: Diagrama elétrico.

Fonte: VOLKSWAGEN (2009).

CAN significa Controller Area Network do inglês, ou seja, rede de controladores locais. Essa rede tornar a estrutura da eletrônica embarcada nos veículos mais flexível, pois é possível reduzir a quantidade de cabos e conectores elétricos. Este sistema de comunicação é baseado em um barramento no qual as informações trafegam entre todas as unidades que estão interligadas na rede, reduzindo assim a quantidade de fios condutores e sensores, onde esse barramento é composto por dois fios que ambos recebem e enviam informações [8].

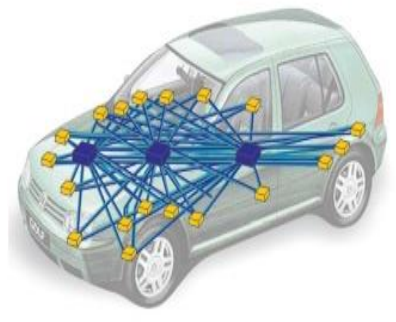

Simulaçăo de um veiculo sem sistoma de comunicatän, ne qust os sensores informam duas ou trés unidades de controle existentes no

Figura 8: Arquitetura eletrônica de um veículo sem e com rede CAN.

Fonte: NOTÍCIAS DA OFICINA (2016).
O sistema eletrônico da transmissão também proporciona um grande intercâmbio de informações com outros sistemas eletrônicos do veículo, que são enviados pela rede CAN tração. São elas: rotação do motor, posição do pedal do acelerador, torque do motor e temperatura do líquido de arrefecimento, a partir da Unidade de Controle do Motor J623; velocidade do veículo, a partir da Unidade de Controle do ABS J104 ou da Unidade de Controle do motor J623; solicitação de troca de marcha, a partir da Unidade de Controle dos Sensores da Alavanca Seletora 1587 ou das borboletas no volante multifuncional via E221; temperatura externa, a partir da Unidade de Controle do Climatronic J255. Além disso, a Unidade de Controle da Transmissão J217 fornece outros sinais suplementares para as outras unidades de controle envolvidas, que são: sinal de liberação de partida para a Unidade de Controle do Motor executar o controle da partida do motor; sinal de solicitação de redução de torque para a Unidade de Controle do Motor na iminência de troca de marcha (via CAN); indicação de modo de condução selecionado, marcha engatada, alertas de ação não consentida e de avarias para o Instrumento Combinado (via CAN); sinal de solicitação de adequação da rotação do motor 
com a marcha a ser engata (para cima ou para baixo) para a Unidade de Controle do Motor via rede CAN [11].

Tabela 1: Componentes do sistema elétrico da transmissão automatizada.

\begin{tabular}{|c|c|c|}
\hline Sensores & Unidades de contrrole & Atuadores \\
\hline $\begin{array}{l}\text { G270 - sensor } \\
\text { de pressão } \\
\text { hidráulica }\end{array}$ & J217 - Transmissão & $\begin{array}{l}\text { N255 - Válvula } \\
\text { do } \\
\text { atuador da } \\
\text { embreagem }\end{array}$ \\
\hline $\begin{array}{l}\text { G182 - sensor } \\
\text { de rotação de } \\
\text { entrada }\end{array}$ & J104 - ABS & $\begin{array}{l}\text { N284 - Válvula } 1 \\
\text { para seleção de } \\
\text { marcha }\end{array}$ \\
\hline $\begin{array}{l}\text { G476 - sensor } \\
\text { de posição da } \\
\text { embreagem }\end{array}$ & $\begin{array}{l}\text { E221 - Controle do } \\
\text { Volante }\end{array}$ & $\begin{array}{l}\text { N285 - Válvula } 2 \\
\text { para seleção de } \\
\text { marcha }\end{array}$ \\
\hline $\begin{array}{l}\text { G604 - sensor } \\
\text { de identificação } \\
\text { de marcha }\end{array}$ & $\begin{array}{l}\text { J285 - Instrumento } \\
\text { Combinado }\end{array}$ & $\begin{array}{l}\text { N286 - Válvula } 3 \\
\text { para seleção de } \\
\text { marcha }\end{array}$ \\
\hline $\begin{array}{l}\text { G616 - sensor } \\
2 \\
\text { de identificação } \\
\text { de marcha }\end{array}$ & $\begin{array}{l}\text { J510 - Relé de } \\
\text { alimentação da } \\
\text { bomba hidráulica }\end{array}$ & $\begin{array}{l}\text { V387 - Bomba } \\
\text { hidráulica }\end{array}$ \\
\hline $\begin{array}{l}\text { F - Interruptor } \\
\text { do pedal do } \\
\text { freio }\end{array}$ & $\begin{array}{l}\text { J587 - Controle dos } \\
\text { sensores da Alavanca } \\
\text { Seletora }\end{array}$ & \\
\hline $\begin{array}{l}\text { F2 - } \\
\text { interruptor } \\
\text { de porta na } \\
\text { unidade da } \\
\text { fechadura lado } \\
\text { condutor F220 }\end{array}$ & J623 - Motor & \\
\hline $\begin{array}{l}\text { F9 - Interruptor } \\
\text { do freio de } \\
\text { estacionamento }\end{array}$ & $\begin{array}{l}\text { J879 - Sistema } \\
\text { Interativo }\end{array}$ & \\
\hline
\end{tabular}

\subsection{Transmissão Automatizada Eletromecânica}

A automação aplicada neste modelo de transmissão é do tipo eletromecânica, tem por característica um sistema mais compacto e simples, além de possuir uma menor quantidade de componentes, basicamente é constituída por uma transmissão manual de 5 velocidades, um atuador de embreagem, um atuador para seleção e outro engate de marchas, além da unidade de controle eletrônica da transmissão e uma alavanca seletora de mudanças que utiliza o conceito chamado "shift by wire" ou seja, não existe qualquer ligação mecânica da alavanca seletora de mudanças até a transmissão e sim uma comunicação CAN. Os atuadores ficam encarregados de realizar os movimentos do processo de troca de marchas antes feito pelo motorista.

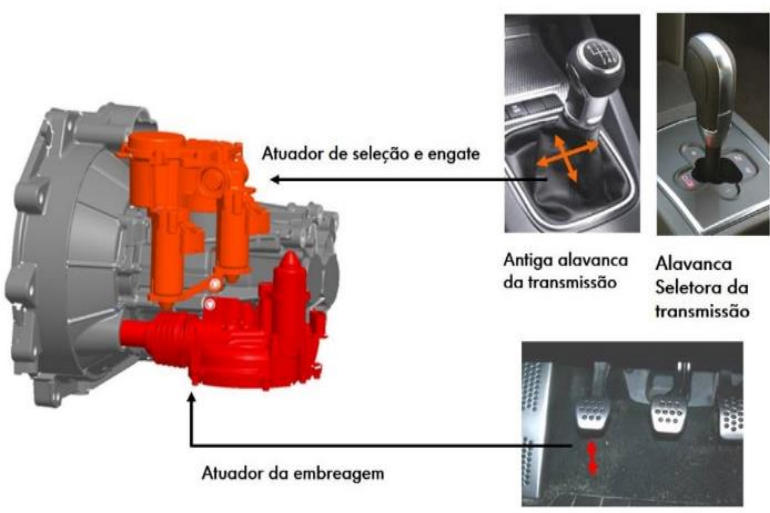

Figura 9: Acionamento da embreagem e alavanca de mudanças automatizados.

Fonte: VOLKSWAGEN (2015).

\subsubsection{ARQUITETURA DA TRANSMISSÃO}

As trocas de marchas são realizadas pelo atuador da embreagem e pelo atuador de seleção e engate. $\mathrm{O}$ atuador da embreagem, com o motor para o atuador da embreagem, se encarrega de acionar a embreagem. O atuador de seleção e engate, com os motores elétricos, executa as trocas das marchas. Tanto o atuador da embreagem como o atuador de seleção e engate são excitados eletricamente pela unidade de controle da transmissão manual automatizada J514 [10].

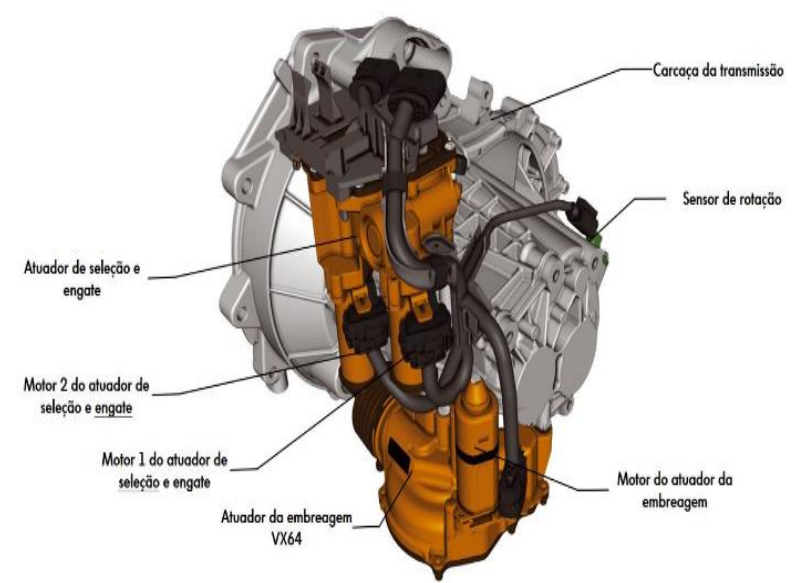

Figura 10:Quadro geral da arquitetura da transmissão. Fonte: VOLKSWAGEN 2015 


\subsubsection{GERENCIAMENTO ELETRÔNICO DA TRANSMISSÃO}

A unidade de controle da transmissão comunica-se com as demais unidades de controle através da rede CAN tração. O sinal de autorização de partida é transmitido para a unidade de controle da rede de bordo por meio de um cabo próprio. As premissas para a autorização de partida são: alavanca seletora na posição $\mathrm{N}$ e pedal de freio acionado. O sinal de liberação de partida tem que ser recebido pela unidade de controle da rede de bordo por ambos canais, para acionar o motor. Os sinais do sensor de posição do atuador da embreagem e do atuador de seleção e engate, assim como do sensor de rotação são enviados diretamente a unidade de controle da transmissão J514. A unidade de controle da transmissão utiliza os sinais recebidos da rede CAN para decidir o momento do fechamento da embreagem e da troca das marchas. Os servomotores são excitados diretamente pela unidade de controle por meio de sinal PWM [10].

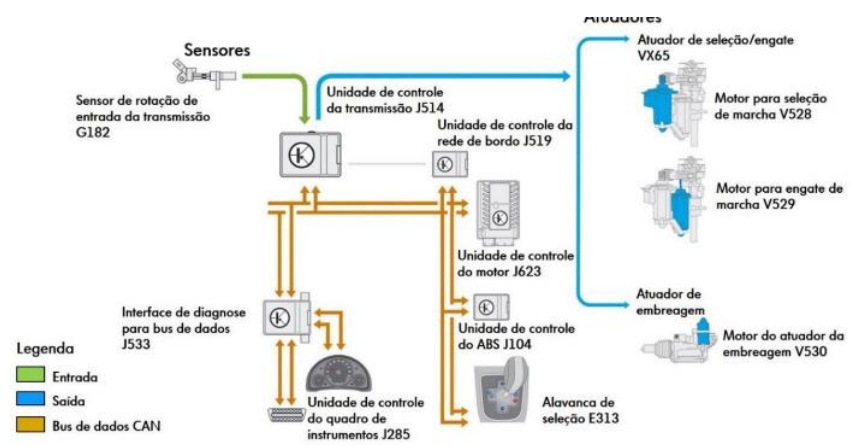

Figura 11: Diagrama do Sistema eletrônico da transmissão automatizada.

Fonte: [10].

\subsubsection{CICLO DE TROCA DE MARCHAS}

Para realização, do ciclo de troca de marchas automatizada, o sistema utiliza como referências os valores de ajuste básicos configurados na unidade de controle da transmissão para ativar os motores de seleção e engate de marchas de forma

simultânea e precisa. A eletrônica da alavanca de mudanças E313 transmite as intenções do motorista para a unidade de controle da transmissão J514, na qual processa a solicitação e aciona atuador de embreagem V530 e VX64 e então a embreagem é aberta [10].

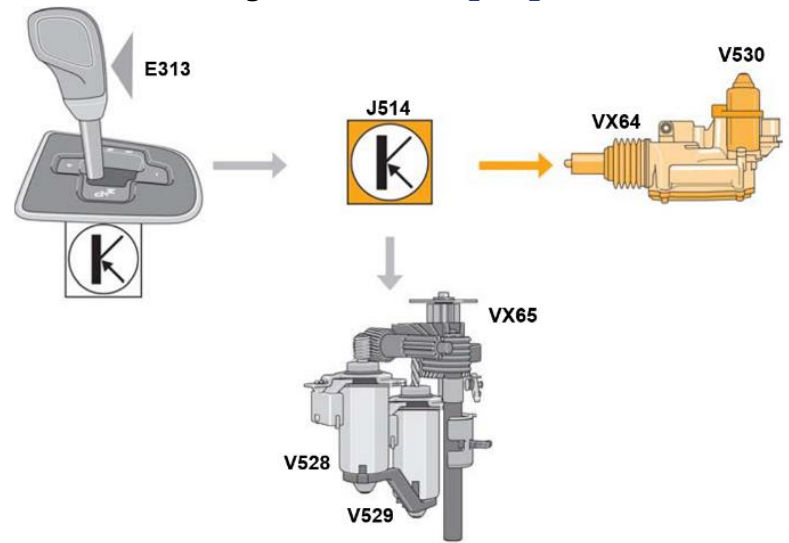

Figura 12: Acionamento do atuador de embreagem Fonte: [10].

O motor elétrico para seleção de marchas V528 e o motor de engate V529, são acionados mediantes a alimentação de corrente elétrica, então o eixo seletor é colocado na posição neutro mediante a um movimento axial realizado pelo motor de engate e ao mesmo tempo o motor de seleção posiciona o eixo seletor com movimento vertical [10].

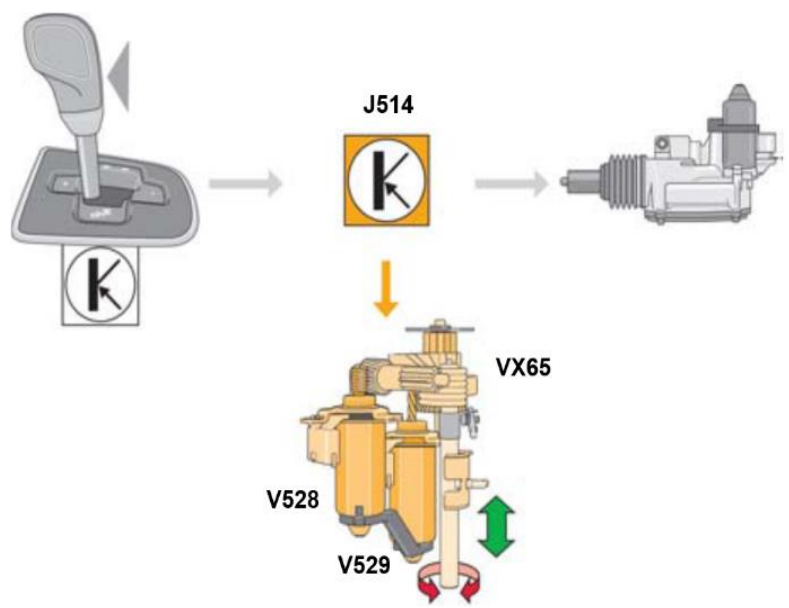

Figura 13: Acionamento da seleção e engate das marchas.

Fonte: [10].

Com o engate da marcha concluído com êxito, a embreagem se fecha, finalizando todo o ciclo de troca de marcha de forma automatizada, proporcionando uma condução bastante confortável e segura pois todo o processo foi realizado pelo sistema sem intervenção do motorista. 


\section{RESULTADOS E DISCUSSÃO}

Optou-se em detalhar os resultados alcançados da pesquisa com base na análise de SWOT, o autor Diniz, descreve em seu livro que: "[...] a análise SWOT é um instrumento muito utilizado nos planejamentos estratégicos das empresas porque força a organização a se confrontar com o ambiente (interno e externo), identificando suas forças, fraquezas, oportunidades e ameaças. 0 objetivo desta análise é gerar informações importantes para tornar a organização mais consciente de suas possibilidades futuras." Esta sigla foi criada a partir de quatro palavras do idioma inglês: Strenght = Força, Weakness = Fraqueza, Opportunities $=$ Oportunidades, Threats = Ameaças [3].

Quadro 1: Análise SWOT da Transmissão Manual Automatizada

\begin{tabular}{|c|c|}
\hline \multicolumn{2}{|c|}{ SWOT } \\
\hline $\begin{array}{l}\text { Forças: } \\
\text { Qualidade do produto; } \\
\text { Maior conforto e segurança; } \\
\text { Redução da fadiga do condutor; } \\
\text { Menor consumo de combustível; } \\
\text { Menos emissões de poluentes; } \\
\text { Otimização dos componentes; } \\
\text { Manutenção e custo menor que } \\
\text { a transmissão automática; }\end{array}$ & $\begin{array}{l}\text { Fraquezas: } \\
\text { Maior custo de reparo } \\
\text { comparando a } \\
\text { transmissão } \\
\text { de troca } \\
\text { manual; } \\
\text { Interrupção da força } \\
\text { durante } \\
\text { a troca de marcha; }\end{array}$ \\
\hline $\begin{array}{l}\text { Oportunidades: } \\
\text { Tendência de crescimento nas } \\
\text { vendas; } \\
\text { Incentivos fiscais para pessoas } \\
\text { com deficiências físicas na } \\
\text { compra de veículos } 0 \mathrm{~km} ;\end{array}$ & $\begin{array}{l}\text { Ameaças: } \\
\text { Aumento nos custos de } \\
\text { produção e matérias- } \\
\text { primas; } \\
\text { Escassez de mão de obra } \\
\text { para manutenção e } \\
\text { reparo } \\
\text { destas transmissões; }\end{array}$ \\
\hline
\end{tabular}

Fonte: Próprio autor.

De acordo com a consultoria Jato Dynamics, entre 2012 e 2016, as vendas de automóveis novos com algum tipo de câmbio que dispensa o uso da embreagem e da troca de marcha manual cresceram $13,5 \%$. Só no primeiro semestre de 2017, 42\% dos emplacados corresponderam a carros equipados com transmissões automáticas, automatizadas, incluindo as de dupla embreagem, e continuamente variáveis (CVT). Esse aumento está relacionado tanto ao crescimento da demanda dos consumidores em busca de maior conforto para encarar o trânsito nas grandes cidades, quanto ao aumento da oferta dessa tecnologia pelos fabricantes. Antes restritas a carros de luxo e com motores de grande cilindrada, hoje até compactos com motor 1.0 possuem algum tipo de câmbio que promete dar um descanso para o pé esquerdo do motorista [2].

[...] Outro aspecto importante da transmissão automatizada I-Motion é a possibilidade de atender cerca de $80 \%$ das pessoas com deficiência física, a um custo consideravelmente inferior ao de uma transmissão automática convencional [7].

Graças à otimização eletrônica da mudança de marcha e à ligação com o controle do motor, a Transmissão Manual Automatizada consegue garantir menor consumo que um carro com transmissão manual. Segundo Cardoso e Queiroz et al. [12] [13], é possível atingir uma redução de consumo de combustível de até $5 \%$. Consumo mais baixo também significa emissões de poluentes mais baixas, especialmente de $\mathrm{CO}_{2}[\mathbf{6}]$.

Para escolher a marcha apropriada o sistema eletrônico da transmissão leva em conta algumas informações como a velocidade do veículo, rotação do motor, acionamento do pedal do acelerador, etc. Porém, vale destacar que por ser uma transmissão manual automatizada, durante as trocas de marchas, o condutor pode perceber a interrupção de força da tração, pois a embreagem é aberta para a seleção e engate preciso da marcha, não se trata de um problema e sim uma característica do próprio sistema.

\section{CONSIDERAÇÕES FINAIS}

Com base na elaboração deste artigo, buscouse ampliar os conhecimentos sobre a aplicação da automação em um sistema de transmissão mecânica automotiva. Segundo as pesquisas bibliográficas, pôde-se entender os conceitos da automação e suas aplicações em dois modelos de transmissões automatizadas além de conhecer suas características de funcionamento.

Foi possível concluir, que a concepção da automação em conjunto com uma transmissão mecânica descritos no Capítulo 3, proporciona inúmeros benefícios tais como: maior nível de segurança, conforto, redução de fadiga do condutor, precisão e otimização dos componentes, menor consumo de combustível e emissões de poluentes especialmente $\mathrm{O}_{\mathrm{CO}_{2}}$ (dióxido de carbono), confirmando a hipótese proposta neste artigo. 


\section{REFERÊNCIAS}

[1] $\mathrm{BOSCH}$, R. Manual de Tecnologia Automotiva. 25. ed. São Paulo: Edgard Blücher, 2005. 1232 p.

[2] CONSIGLIO, T. CARROS COM CÂMBIO AUTOMÁTICO JÁ REPRESENTAM MAIS DE 40\% DAS VENDAS DE OKM: Nos últimos cinco anos, carros com câmbio automático, automatizado e CVT cresceram 13,5\%. 2017. Revista Auto Esporte. Disponível em: https://revistaautoesporte.globo.com/Noticia s/noticia/2017/08/carros-com-cambioautomatico-ja-representam-mais-de-40-dasvendas-de-0km.html. Acesso em: 25 jun. 2018.

[3] DINIZ, A. L. M. Estratégias de Gestão e Organização Empresarial. São Paulo: Pearson Education do Brasil, 2014. 119 p. Disponível em:

http://senaipe.bv3.digitalpages.com.br/users/ publications/9788543004983/pages/-8. Acesso em: 24 jun. 2018.

[4] FONSECA, R. L. da. Tire dúvidas sobre as marchas e o sistema de transmissão de um carro: Veículos precisam de uma transmissão por causa das rotações do motor. 2008.

Especial para o G1. Disponível em: http://g1.globo.com/Noticias/Carros/0,MUL7 58298-9658,00-

TIRE+DUVIDAS+SOBRE+AS+MARCHAS+E+ $O+$ ISTEMA+DE+TRANSMISSAO+DE+UM+C ARRO.html. Acesso em: 15 set. 2008.

[5] GROOVER, M. P. Automação Industrial e Sistemas de manufatura. 3. ed. São Paulo: Pearson Education do Brasil, 2010. $583 \mathrm{p}$.

[6] MAGNETI MARELLI (Brasil). AMT (Transmissão Manual Automatizada). 2018. Disponível em: <https://www.magnetimarelli.com/pt/node/ 4982>. Acesso em: 24 jun. 2018.

[7] NOTÍCIAS DA OFICINA: edição 36., no 252, novembro de 2014, trimestral. São Paulo: Germinal, nov. 2014. Disponível em: https://www.reparadorvw.com.br/noticiasda-oficina/edicoes/2014\# revisa-edicao252/1. Acesso em: 25 jun. 2018.

[8] NOTÍCIAS DA OFICINA: edição 38., no 269, junho de 2016, mensal. São Paulo: Germinal, 2016. Disponível em:

https://www.reparadorvw.com.br/noticias- da-oficina/edicoes/2016\# revisa-edicao269/1. Acesso em: 31 jul. 2018.

[9] SILVEIRA, Paulo R. da; SANTOS, Winderson E.. Automação e Controle Discreto. 9. ed. São Paulo: Érica, 2015.

[10] VOLKSWAGEN (Brasil). Câmbio manual automatizado de 5 marchas OCT: Desenho e funcionamento. São Paulo: Academia Volkswagen, 2015. 40 p. (SSP 512 - Câmbio Manual Automatizado de 5 Marchas 0CT).

[11] VOLKSWAGEN (Brasil). Transmissão Automatizada ASG. São Paulo: Academia Volkswagen, 2009. 40 p. (SSP 009br Transmissão Automatizada ASG).

[12] QUEIROZ, C.; MELO, E.; CALABREZ, F. Revisão dos Sistemas de Transmissão Automotiva. Monografia. Fatec Santo André, 2015.

[13] CARDOSO, J. Estudo das Melhores Práticas Sobre A Vantagem Tecnológia da Transmissão Automática De Veículos de Passeio com Relação ao Consumo de Combustível, 2012. 62 f. (Monografia) Pós-Graduação em Engenharia Automotiva. Escola de Engenharia de Mauá, Instituto Mauá de Tecnologia, São Caetano do Sul, 2012. 